\title{
The Role of Contemporary Childbearing Postponement and Recuperation in Shaping Period Fertility Trends
}

\author{
Tomas Frejka
}

\begin{abstract}
This paper outlines a method that analyses how cohort and period childbearing postponement and recuperation (P\&R) are reflected in total period fertility rate (TPFR) trends in low-fertility populations in recent decades. The method is rooted in the trailblazing ideas developed by Ryder (1951 and 1964), namely that childbearing P\&R occurs in the life of individual women and can be summarised in the lifetime experiences of birth cohorts. Cohort childbearing age patterns are then translated into period childbearing age patterns and the effects of the P\&R process on the TPFRs are revealed by summarising period ASFRs of young women and of older women and analysing their interaction over time in 36 low-fertility populations. The method is complementary to methods pioneered by Bongaarts and Feeney (1998) which estimate tempo-adjusted TPFRs. These demonstrate the degree to which TPFRs are distorted. The method described in this paper reveals the internal mechanism generating TPFR trends; it exposes the demographic structural causes generating TPFR trends and demonstrates why TPFRs are moving in a certain direction.

The following findings stand out:
\end{abstract}

1. All low-fertility populations have experienced TPFR troughs at some point during the past four decades. The troughs occurred because low fertility among young women of young cohorts starting to postpone childbearing overlaps with low fertility among older women of older cohorts who had not postponed births. The troughs occurred in Western countries mostly during the early 1980s and in Central and Eastern Europe around 2000.

2. The structural causes of the increase in TPFRs in the late 1990s and early in the $21^{\text {st }}$ century were different in Western countries compared to Central and Eastern Europe. The former were experiencing the concluding phases of the P\&R process. In contrast, in Central and Eastern Europe populations were experiencing the initial phases of childbearing P\&R. It was a historical coincidence that TPFRs were increasing in most low-fertility populations almost simultaneously around the beginning of the $21^{\text {st }}$ century.

3. These TPFR increases were predominantly the consequence of changes in cohort childbearing age patterns, i.e. changes in the timing of fertility. They were not generated by fertility quantum increases. During this period in almost all the low-fertility countries TPFRs were rising while corresponding total cohort fertility rates were declining. 
Keywords: Cohort childbearing age patterns - Childbearing postponement and recuperation - Effects on total period fertility rates - Low-fertility populations

\section{Introduction}

Trends of total period fertility rates (TPFRs) reflect two processes: quantum fertility trends and evolving changes in childbearing age patterns. This paper focuses primarily on analysing the latter in low-fertility populations over the past half century. It reports on empirical research which investigates how TPFRs trends are shaped by changing age patterns of fertility, more specifically, by the interaction of childbearing postponement and recuperation $(\mathrm{P \& R})^{1}$ because that is the overriding mode of change in the late $20^{\text {th }}$ and early $21^{\text {st }}$ centuries. This research is based on Ryder's findings in his pioneering opus (1951: 63-96) on how cohort age patterns of childbearing can be translated into period fertility age patterns, it explores the demographic internal structural mechanism shaping TPFRs. It provides additional insights which have not been revealed heretofore by other methods exploring the timing of fertility, namely those initiated by Bongaarts and Feeney (1998) estimating tempo-adjusted period total fertility rates. In principle, these period fertility adjustment methods illustrate the extent to which TPFRs are distorted, whether these are inflated or deflated, i.e. whether TPFRs would be lower or higher if the timing distortions were removed. The analysis of the effects of changing cohort childbearing age patterns over time and the resulting interaction of childbearing advancement or postponement among young women and childbearing loss or recuperation among older women reveal the formal demographic structural reasons for particular TPFR trends, i.e. why TPFRs are declining, stable or increasing.

The paper begins with a section discussing issues that are relevant with respect to understanding the research project. The next section outlines the employed method. It continues with an analysis of the ways in which changing cohort and period childbearing patterns modify TPFR declines and troughs as well as increases in 36 low-fertility countries. The paper subsequently deals with a few corollary issues before ending with a summary and conclusions.

\section{$2 \quad$ Antecedents}

In a path-breaking paper Hajnal (1947) reviewed issues of measuring fertility applied at the time, examined their inadequacies and proposed methods of analysis that facilitate an improved understanding of childbearing levels and trends. Hajnal demonstrated that the increase in fertility rates - crude birth rates as well as net

1 Concept definitions, complexities and qualifications will be discussed below. 
and gross reproduction rates - in the mid-1940s in a number of Western countries and the rapid rise in fertility in the 1930s in Germany was "due to the making up of postponed births." Hajnal demonstrated theoretically and empirically the apparent dilemma of period rates increasing (or declining) considerably at the same time as cohort rates remained stable.

In a similar vein, the goal of this study is two-fold:

1. To devise a method that follows the process of cohort and period childbearing postponement and recuperation and its reflection in total period fertility levels and trends in low-fertility populations during the late $20^{\text {th }}$ and early $21^{\text {st }}$ centuries.

2. The method is then applied to explore actual developments in 36 low-fertility societies during the second half of the $20^{\text {th }}$ century and the first years of the $21^{\text {st }}$ century, to explore the interaction of childbearing postponement and recuperation trends on TPFRs in these populations.

Typically during the past several decades age patterns of childbearing in lowfertility populations have been aging. On the one hand, age-specific fertility rates of young women have been declining in comparison to previous generations and this has been denoted as childbearing postponement (delay). ${ }^{2}$ On the other, increases in ASFRs of older women compared to their predecessors were considered as childbearing recuperation (recovery or catching-up). As long as one deals with statistical measures, the analysis is relatively straightforward, although not necessarily simple. The terms, however, are ambiguous (Frejka/Sardon 2004: 17-18; Ni Bhrolcháin/Toulemon 2005: 87-88; Sobotka et al., 2011: 3-4). Linguistically, the term "postponement" means that what is being postponed will take place in the future. In reality frequently there is not a good match between the magnitude in the fall in childbearing when women are young and the size of the subsequent rise in fertility. The numbers of "recuperated" births may be smaller or larger than those of the "postponed" ones. Another complexity arises when attempting to decipher the behavioural underpinnings of childbearing postponement. A number of questions arise when attempting to establish whether women and/or couples have specific intentions to have a/another birth later in life. The present exploration does not deal with these issues. For the purposes of this project any decline in fertility of young women is considered a childbearing postponement, and analogously a fertility increase of older women is considered a childbearing recuperation.

2 The term "postponement" was used already in the middle of the 20th century. Ryder (1951: 67) citing Hajnal (1950) and Sauvy (1948) notes: "In the explanation of the course of fertility rates in the Western world in the past twenty years, the term 'postponement' has been widely used." Ryder defines "postponement" "as the action of couples who ..... do not bear their children when they would ordinarily have been expected to bear them, but rather defer these births to a later more favourable time." The "past twenty years" in the citation include the period of the 1930s when one half of Europe's populations reached below replacement period fertility rates (Kirk 1946: 54-57). For instance, in 1933-34 the net reproduction rate in Austria was 0.66 and in 1933 in Germany it was 0.70 . 
The massive postponement and recuperation of childbearing in low-fertility societies have been important sociological and demographic developments during the past half century. Changing childbearing age patterns have been integral components in the evolution of family formation, the diversity of marriage and cohabitation forms and trends, and the "Second Demographic Transition" (Billari 2008; Billari/Kohler 2004; Bongaarts/Feeney 1998; Frejka et al. (eds.) 2008; Frejka et al. 2010; Frejka/Sardon 2004; Goldstein et al. 2009; Jones et al. 2009; Kohler at al. 2002; Lesthaeghe 1995 and 2001; Lesthaeghe/van de Kaa 1986; Sobotka 2004a/b; Sobotka/Toulemon 2008).

Concurrently also changes in the level of childbearing, i.e. mainly declines in fertility quantum, have been occurring during the past half century. These trends are discussed in innumerable publications (for instance, Bongaarts 2001 and 2002; Bourgeois-Pichat 1987; Calot/Blayo 1982; Chasteland/Chesnais 1997; Chesnais 1998; Frejka/Ross 2001; Frejka/Sardon 2004 and 2009; Hobcraft 1996; Lesthaeghe 2001; Ryder 1986; Sardon 2004; Teitelbaum/Winter 1985; Westoff 1983). When depicting fertility trends with completed cohort fertility rates a clear picture of quantum changes over time is communicated. ${ }^{3}$ Because such a portrayal has the unavoidable shortcoming that this can be done only after the youngest birth cohorts have completed their childbearing and thus it fails to provide up-to-date information, fertility trends are frequently depicted by employing total period fertility rates (TPFRs). ${ }^{4}$ The latter approach has the less obvious shortcoming that TPFRs contain and reflect not only quantum fertility changes but also changes in the timing of childbearing. Increasingly, over a period of several decades demographers have demonstrated that changes in the timing of births "distort" TPFRs (see, for instance, Hajnal 1947; Ryder 1951 and 1964, Bongaarts/Feeney 1998). When births are being postponed there are less of them per year, i.e. TPFRs are deflated, and vice versa, when births are advanced there are more of them per year, i.e. TPFRs are inflated.

Bongaarts and Feeney (1998) initiated efforts to devise methods of developing tempo-adjusted total fertility rates that remove temporary effects of changes in childbearing timing. These endeavours have been thoroughly discussed in the literature. Some researchers pointed out shortcomings in the Bongaarts-Feeney adjustment (for instance, Schoen 2004, and van Imhoff 2001). Others have strived to further advance and improve these methods (for instance, Bongaarts/Feeney 2006; Bongaarts/Sobotka 2010; Goldstein et al. 2009; Kohler et al. 2002; Lesthaeghe 2001; Lesthaeghe/Willems 1999; Ortega/Kohler 2002; Philipov/Kohler 2001; Schoen 2004; Sobotka 2003 and 2004a/b; Sobotka/Lutz 2009). Various forms of the adjusted total fertility rates have been widely used during the past decade.

3 The average total cohort fertility rate in the low fertility countries has declined from 2.48 births per woman in the 1932 birth cohort to 2.10, 1.97 and 1.80 in the 1946, 1960 and among the latest cohorts for which data were available, i.e. the 1966 to 1971 cohorts, respectively (author's calculations).

4 The average total period fertility rate in the low fertility countries has changed from 3.15 births per woman in 1950 to $1.90,1.53$ and 1.55 in 1980, 2000 and 2006-2008, respectively (author's calculations). 
The present paper explores a complementary approach to explaining and understanding total period fertility rate levels and trends. It is a combined cohort and period perspective based on the fact that during the postponement and recuperation process successive birth cohorts with changing age patterns of childbearing overlap. These overlapping age patterns of cohort childbearing can be translated into period fertility trends of young women postponing childbearing which interact with fertility trends of older women who are recuperating births and their interplay is reflected in levels and trends of TPFRs.

Thus far the repercussions of the overlay of childbearing age patterns of successive cohorts as well as the duration of the postponement and recuperation process on trends of total period fertility rates in the late $20^{\text {th }}$ and early $21^{\text {st }}$ centuries have rarely been analysed, demonstrated and documented. ${ }^{5}$

Research reported on in this paper explores the detailed age-specific mechanism, the interaction of fertility trends of young and older women of overlapping birth cohorts, which underlie trends in total period fertility rates in 36 low-fertility countries. In the present context the term "mechanism" is not meant to imply any substantive causation. It is used to describe the dynamics of TPFR trends resulting from the interaction of changing childbearing trends of young and older women that were translated from changing fertility age patterns of overlapping cohorts. Thus the analysis starts with childbearing behaviour of cohorts which has been shaped by their life course history that includes period effects. In other words, this investigation recognizes the coinciding importance and validity of both cohort and period effects.

The present time is suitable and favourable for a detailed empirical investigation of the postponement and recuperation process in low-fertility countries. This process has been in progress in many of these countries over the past 40 to 50 years and data to conduct the research are now available. The availability of sufficiently long series of detailed single-year age-specific fertility rates in the data banks of the Observatoire Démographique Europeén ${ }^{6}$ and of the Human Fertility Database ${ }^{7}$ make it possible to analyse the fertility postponement and recuperation process. ${ }^{8}$

5 Frejka (2008: 157) appears to be an exception.

6 Jean-Paul Sardon, Director (odeurope@wanadoo.fr).

7 The Human Fertility Database (http://www.humanfertility.org/cgi-bin/main.php) is located at the Max Planck Institute for Demographic Research.

8 The data bank of the Observatoire Démographique Europeén will gradually be replaced by the Human Fertility Database (HFD). Work on the HFD began in 2007 as a collaborative project involving research teams at the Max Planck Institute for Demographic Research (MPIDR) in Rostock (Germany) and the Vienna Institute of Demography (VID) in Vienna (Austria). The HFD is directed by J. R. Goldstein, V. Shkolnikov and T. Sobotka. 


\section{$3 \quad$ The method}

Following the reasoning outlined by Ryder (1951: 63-96), childbearing postponement and recuperation occurs in the life of individual women and can be summarised in the lifetime experiences of birth cohorts. Almost invariably cohort childbearing age patterns change from one year to the next. Because each total period fertility rate (TPFR, $S_{\mathrm{y}}$ ) consists of individual age-specific fertility rates (ASFR, $\mathrm{f}_{\mathrm{c}, \mathrm{y}}(\mathrm{x})$ ) of the respective birth cohorts (c) in a particular year (y), TPFRs $\left(\mathrm{S}_{\mathrm{y}}\right)$ are a crosssection of individual ASFRs $\left(f_{c, y}(x)\right)$ selected from the respective cohorts. Thus an array of ASFRs from corresponding cohorts constitutes ASFRs of specific years. In the demographic literature this is commonly referred to as "demographic translation" (e.g., Ryder 1951 and 1964).

$S_{y}=\sum_{x=15}^{49} f_{c-x+15, y}(x)=f_{c, y}(15)+f_{c-1, y}(16)+\ldots . .+f_{c-34, y}(49)$

As depicted in Figure 1 the 1980 TPFR, for example, consists of ASFRs from birth cohort 1965, age 15, to that of the 1931 cohort, age 49. Because fertility trends of younger women on the one hand, and older ones, on the other, tend to go almost exclusively in similar directions, the respective period ASFRs can be cumulated for young $\left(F_{a}\right)$ as well as for older women $\left(F_{b}\right)$.

$S_{y}=F_{a}+F_{b}$

where $F_{a}=\sum_{x=15}^{28} f_{c-x+15, y}(x)=f_{c, y}(15)+f_{c-1, y}(16)+\ldots . .+f_{c-13, y}(28)$

$F_{b}=\sum_{x=29}^{49} f_{c-x+15, y}(x)=f_{c-14, y}(29)+f_{c-15, y}(30)+\ldots . .+f_{c-34, y}(49)$

The effects of the fertility postponement and recuperation process on the TPFRs, $S_{y^{\prime}}$ are revealed by analysing the interaction of the cumulated ASFRs of young women, $F_{a^{\prime}}$ with the cumulated ASFRs of older women, $F_{b^{\prime}}$ over time. ${ }^{9}$

In sum, the method investigates the effects of changing cohort childbearing age patterns translated into corresponding period childbearing age patterns on levels and trends of total period fertility rates. This rather complicated process will now be discussed in detail.

9 Note that this procedure includes the childbearing behaviour of all cohorts, including those that have not yet concluded their reproductive periods, and is thus up-to-date. The 2000 TPFR, for instance, consists of ASFRs from birth cohorts 1951 to those of the 1985 cohort (Fig. 1), which in 2010 is still in the midst of its childbearing period. 
Fig. 1: Schematic relationship between cohort age-specific fertility rates (diagonals, 1920-1990) and total period fertility rates (columns, 1965-2010)

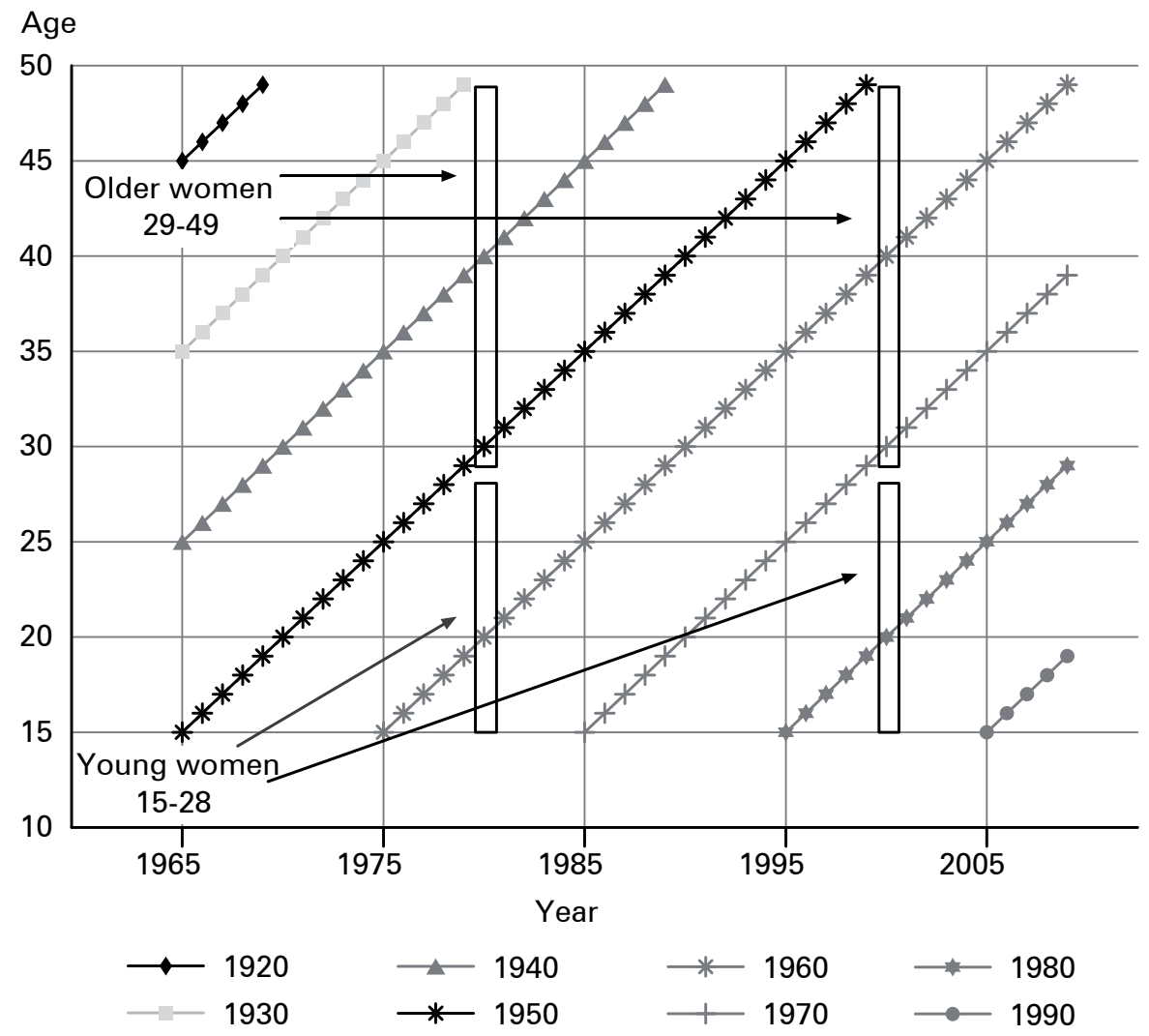

Source: Author's illustration of equations

\subsection{Fertility dynamics: Individual birth cohorts}

The process of postponement and recuperation can be defined as women of a specific birth cohort bearing children at a later age compared to an older, base (or reference) cohort. Typically during this process age-specific fertility rates (ASFRs) while women are in their teens and early as well as mid-twenties are lower in the younger birth cohort, whereas when these women reach their late twenties, thirties and forties, the ASFRs are higher than in the base cohort. This process can be depicted and measured by comparing the age-specific childbearing pattern of the cohort in question with the age-specific childbearing pattern of a base cohort in various ways (Fig. 2, panels A \& B).

In Figure 2 the 1957 age-specific childbearing pattern of Denmark's population is compared with the 1947 ASFRs. The latter is selected because it is approximately 
Fig. 2: $\quad$ Age-specific fertility rates, Denmark, birth cohorts 1947 and 1957

A. Age patterns of fertility, birth cohorts 1947 and 1957

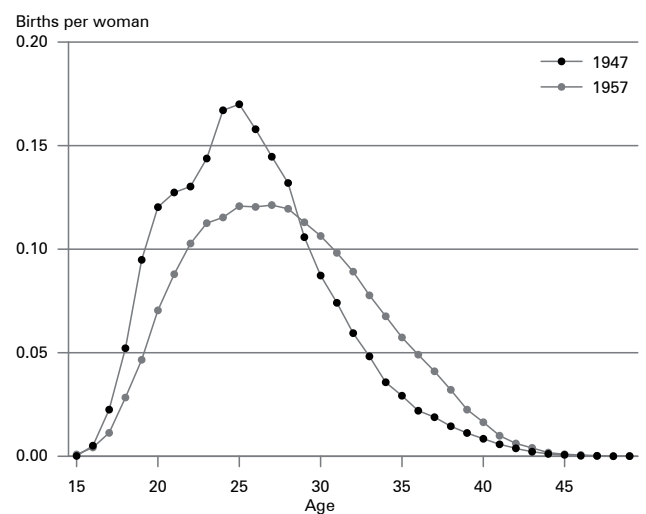

B. Differences in cumulative age-specific cohort fertility rates between 1947 and 1957 birth cohorts

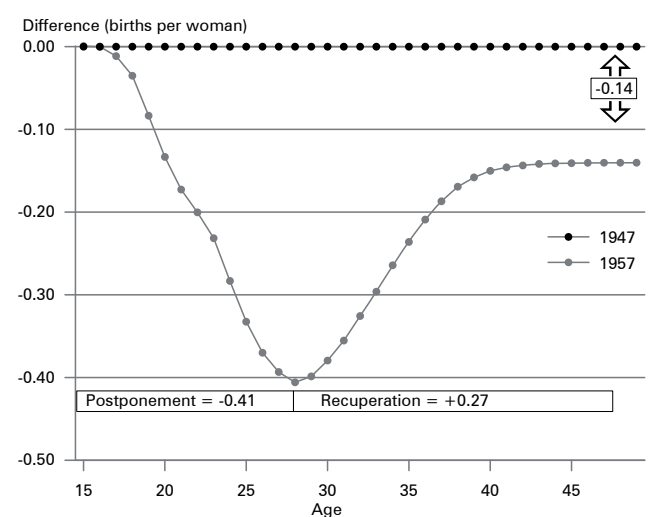

Source: Observatoire Démographique Européen 2010

the birth cohort after which childbearing postponement and recuperation started during the late 1960s in Denmark. This is a typical example of the beginning of the P\&R process in Western countries.

In Figure 2, panel A the two age-specific childbearing patterns are juxtaposed. The 1957 curve is lower to the right of the 1947 curve up to age 28 illustrating the degree of postponement. Starting with age 29 the curve of the 1957 birth cohort is higher than the 1947 curve illustrating the extent of recuperation. The cumulative value of lesser childbearing of the 1957 cohort up to age 28 included was minus 0.41 births per woman and the cumulated value of excess childbearing of the 1957 cohort above age 28 was plus 0.27 births per woman. The difference between these two values, minus 0.14 births per woman, is also the difference between the total cohort fertility rates of the two birth cohorts, 2.00 (1947) and 1.86 (1957), which is the quantum change between the two cohorts.

In Figure 2, panel B the base cumulated age-specific values of the 1947 cohort are defined as equal to zero and the cumulated values of the 1957 cohort are compared to this base. The downward slope of the 1957 curve up to a trough at age 28 depicts the postponement phase of childbearing. The trough of the 1957 curve at age 28 has the familiar value of minus 0.41 births per woman. Following the trough the 1957 curve slopes upward depicting the recuperation phase. The final value of the curve at age 49 is minus 0.14 births per woman, which is the final outcome of the postponement and recuperation process in the 1957 compared to the 1947 cohort.

Another way to demonstrate that the postponement and recuperation process has begun is to compare the proportions of childbearing of the respective cohorts prior to and after the trough age. In Denmark in the 1947 birth cohort $74 \%$ of births 
were born up to and including age 28 compared to only $57 \%$ of all births of the 1957 cohort up to the same age.

\subsection{Fertility dynamics: Changing cohort childbearing age patterns and translation to period rates}

Once the process of childbearing postponement and recuperation gets under way, it tends to progress from one birth cohort to the next quite systematically, although not necessarily at an even pace. In Figure 2 the difference between the childbearing age patterns of two birth cohorts ten years apart are specified and compared. Figure 3 illustrates how the childbearing patterns changed from one cohort to the next over time, in this case between the 1947 and the 1957 birth cohorts, as well as before and afterwards.

This process viewed from a period perspective reveals a principal observation which is at the core of the analysis presented in this paper. The 1983 total period fertility rate (1.38 births per woman) in Denmark was relatively low because of the specific overlay of cohort childbearing age patterns of different birth cohorts. In 1983 childbearing was low among older women born during the 1940s and early 1950s, because most of their children were born when they were young, they had a young childbearing age pattern. At the same time, women born in the late 1950 s and the 1960s had few births when they were young; they "postponed" their births. As will be demonstrated below, this particular combination of low fertility at older ages of older cohorts combined with low fertility of younger cohorts when young was experienced by all low-fertility populations at some point between the mid 1970s and the mid-2000s.

Why did the TPFR decline by as much as 0.54 births per woman, i.e. by $28 \%$, in the ten years between 1973 and 1983? The main structural reason was that the respective TPFRs consisted of cross-sections of ASFRs from rapidly changing cohort childbearing age patterns. In addition, the Danish population was also experiencing some fertility quantum decline at the same time. The quantum decline between the roughly corresponding 1947 and the 1957 TCFRs, the two cohorts, who experienced their peak childbearing ages around 1973 and 1983, respectively, was 0.14 births per woman, i.e. seven percent. The difference between the two values was the approximate contribution of changing childbearing age patterns to the TPFR decline between 1973 and 1983: 0.54 minus 0.14 equals 0.40 births per woman, i.e. about three-quarters of the TPFR change between 1973 and 1983 was due to changing cohort childbearing patterns.

This is one particular case of the interrelationship between changing cohort childbearing age patterns and a TPFR trend. In order to be able to analyse the impact of the changing cohort childbearing patterns on long-term TPFR trends, cohort ASFRs have to be translated into period ASFRs. These are shown in Figure 4 for Denmark's population for the period 1970 to 1990, separately for young women up to age 28 in panel A and for older women aged 29 to 39 in panel B. They depict in detail the postponement and recuperation process from a period perspective at individual ages. 
Fig. 3: Age-specific fertility rates, Denmark, birth cohorts 1927 to 1977 during the period 1960-2006

Births per woman

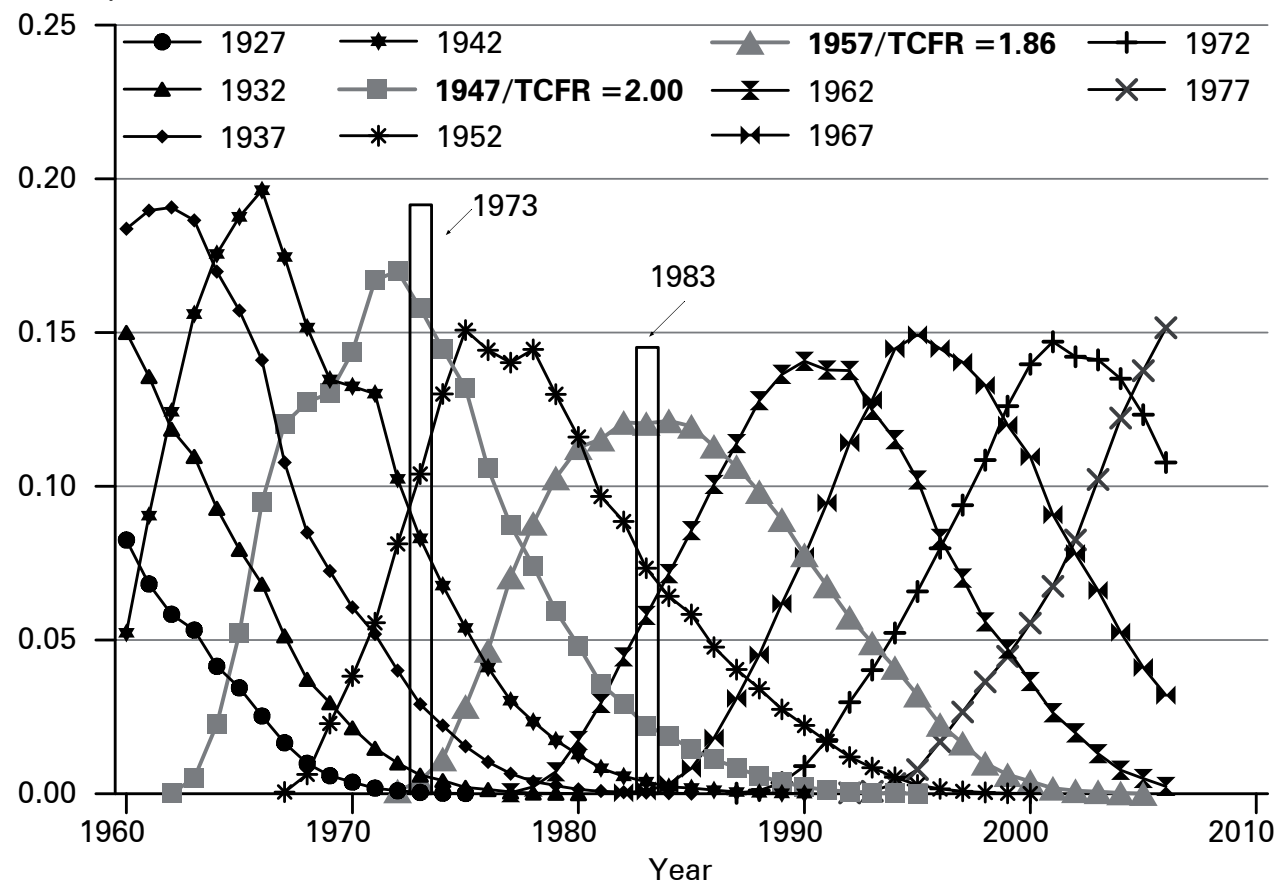

Source: Observatoire Démographique Européen 2010

The trends in the shaded areas illustrate the initial stage of postponement between 1973 and 1983 (Fig. 4). The ASFRs of young women declined at all ages substantially (Fig. 4, Panel A). More specifically, for example, the period ASFR for age 18 was lower by $35 \%$ in 1983 compared to 1973, at age 21 by $56 \%$, and at age 24 by about $65 \%$. There was some decline even among older women presumably reflecting the overall fertility quantum decline (Fig. 4, panel B).

Starting approximately in 1983 the curves for all ASFRs above ages 26-27 turned upward. Many of the young women who did not bear children between 1973 and 1983 , i.e. who were then "postponing" their childbearing, were catching up on their childbearing, they were recuperating a proportion of the births they did not have earlier, after 1983. For instance, period ASFRs in 1990 were higher than in 1983 by 44, 61 and $78 \%$ for ages 30, 33 and 36, respectively (Fig. 4, panel B). 
Fig. 4: Period age-specific fertility rates, Denmark, 1970-1990, ages 18, 21, 24 and 27 (panel A), 30, 33, 36 and 39 (panel B)

A. Period ASFRs, ages 15 to 28

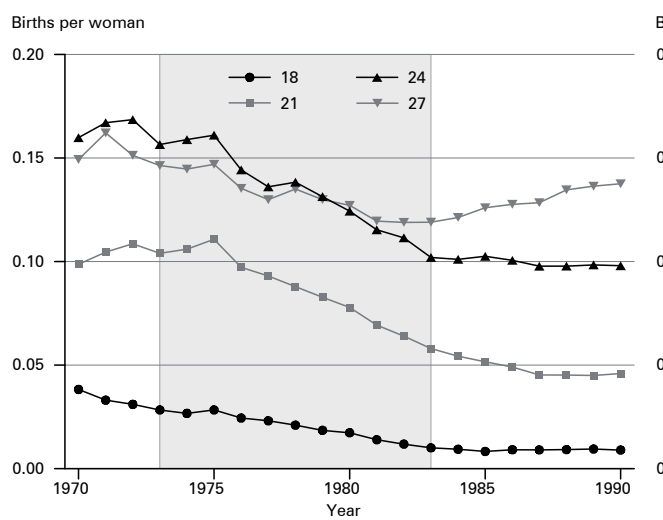

B. Period ASFRs, ages 29 to 39

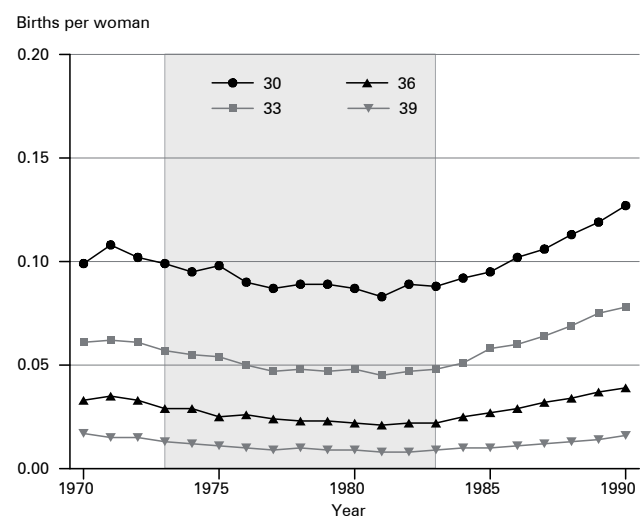

Source: Observatoire Démographique Européen 2010

\subsection{Fertility dynamics: Changing cohort childbearing age patterns and their role in shaping total period fertility rates}

The next step is to devise a procedure to explain and analyse the interrelations between childbearing postponement and recuperation, and trends of total period fertility rates.

It is a matter of course that childbearing postponement occurs among young women and recuperation among older women. The period ASFRs which have been translated from cohort ASFRs of young women as well as those of older women can be cumulated. The cumulated measures hardly ever contain offsetting ASFR trends of individual ages (see Fig. 4). These cumulated measures express childbearing trends of young and of older women. A decline in the cumulated fertility rate of young women illustrates a trend of postponement. Stability or even an increase means that postponement has ceased. And vice versa for older women, an increase in the cumulated fertility rate illustrates the trend of recuperation. Stability or even a decline means that recuperation has ceased. By definition the sum of the cumulated period ASFRs for young and for older women for each year equals the total period fertility rate.

The clincher is to identify the age which is the best approximation dividing young women from the older ones. This age varies slightly over time in a particular population and varies between populations, albeit within a narrow range. It is usually in the mid to late twenties, i.e. between the ages of 24 to 30 . In Western populations it is around age 28 (see, e.g., Fig. 2, panel B), but it can be lower (e.g., in Central and Eastern Europe) or higher (e.g., in Southern Europe). For purposes of long-term analyses it is acceptable to select one age for all cohorts which divides young women from 
older ones, even though it might be changing over time and off by a few years for some individual cohorts. To identify and then use the real dividing age for each birth cohort when investigating 40 to 50 cohorts in a longitudinal analysis of a country and doing so in over 30 populations would make the investigation cumbersome. In this project the decision was made to use the age group 15-28 to define young women and 29-49 for older women for all countries and all cohorts. Admittedly, the use of these age groups causes some inaccuracies.

\subsection{Fertility dynamics: A postponement and recuperation model}

Based on the experience of those populations that have completed, or have gone through a considerable part of the path towards the end of the P\&R process, a mode ${ }^{10}$ has been built. ${ }^{11}$ In the model (Fig. 5) the cumulated fertility rates of young women interact with the cumulated fertility rates of older women. It is important to constantly keep in mind that changing cohort fertility age patterns underlie the trends of the cumulated period fertility rates of the respective age groups; for instance, as cohorts age, the bulk of the young women of the mid-1970s constitute the bulk of the older women in the mid-1980s (see sections 3.2 and 3.3 above). The trend of the total period fertility rate equals the sum of the cumulated fertility rates of the two age groups in each year, and TPFR values in individual countries equal officially published data.

The model is used as a standard for comparison for all populations (Fig. 5). A real period of years is used in the model with the P\&R process starting in the mid 1970s, i.e. at a time when the total period and the total cohort fertility rates were approximately equal in a number of Western countries. The beginning of the postponement and recuperation process is preceded by the end of a substantial quantum fertility decline when childbearing of both young and older women was decreasing during the end of the "baby-boom" (Fig. 5).

The model consists of four phases based on the experience of populations that were in the advanced stages of the postponement and recuperation process in the mid 2000s: ${ }^{12}$

1. Declining TPFR (phase 1): Childbearing is being postponed among young women for about 10 years, thus their fertility is declining. These women tend to manifest a considerable propensity to limit their childbearing. The fertility trend of older women remains stable because these are the women of the older cohorts that do not yet have births to recuperate, however, towards the end of this phase there may be an incipient childbearing recuperation. At

$\overline{10}$ In the present context the concept "model" is used to depict a generalised description of the completed postponement and recuperation process against which specific developments in any population can be compared.

11 The principal countries used for constructing the model were Denmark, Norway, Belgium, The Netherlands and New Zealand.

12 The societal environment in which childbearing behaviour takes place is not discussed in this paper. Important literature on this topic is noted in section 2. Antecedents above. 
Fig. 5: $\quad$ Model depicting phases of childbearing postponement and recuperation, total cohort fertility rate lagged by 30 years TCFR (-30)), total period fertility rate (TPFR), cumulated period fertility rate ages 15-28 (CPFR 15-28) and cumulated period fertility rate ages 29-49 (CPFR 29-49)

Fertility rate (births per woman)

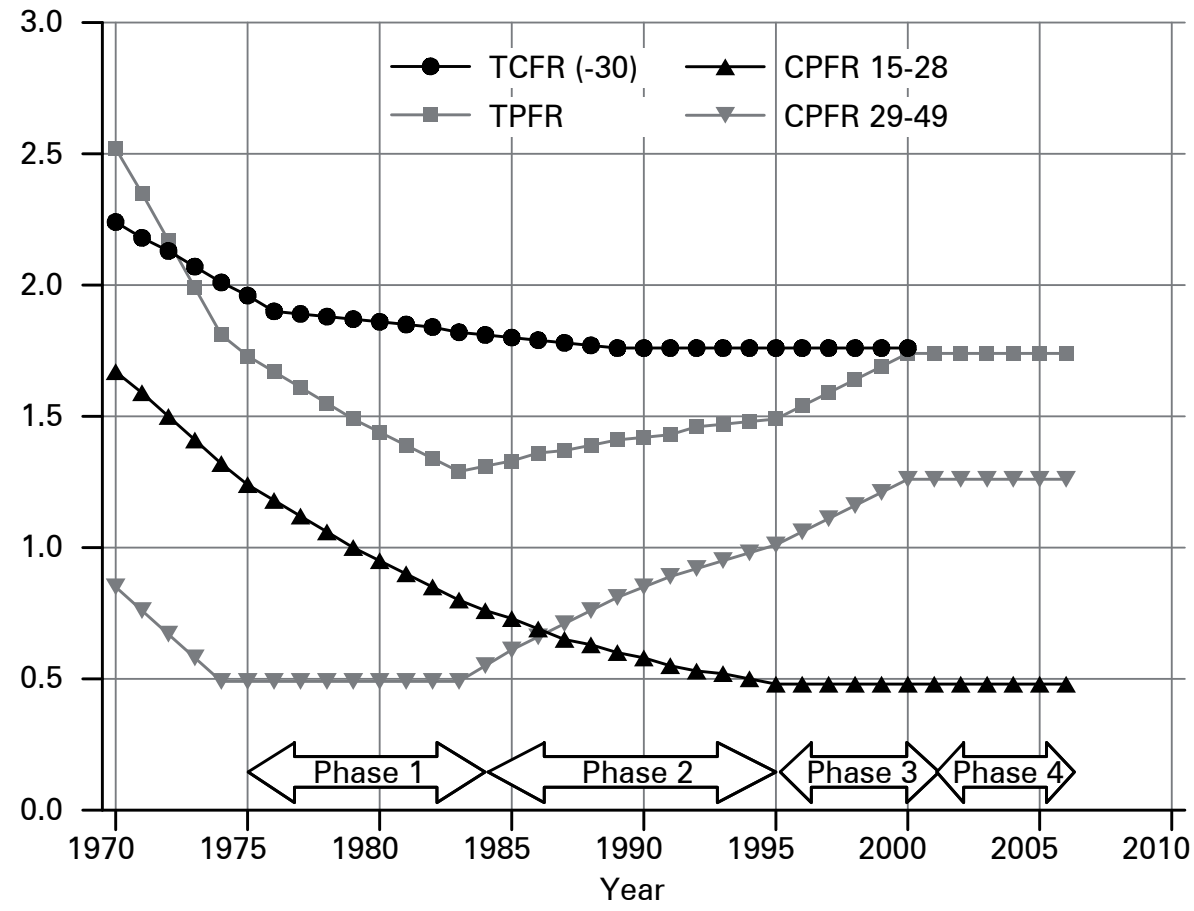

Quelle: own design

the end of this phase the TPFR is at its lowest level with its largest degree of distortion which is also the largest distance from the "corresponding" TCFR lagged by the average age of childbearing. This lowest point represents a TPFR trough which is generated at the end of phase 1 and beginning of phase 2 when the extent of fertility decline due to childbearing postponement of young women is offset by the emerging extent of recuperation of older women. The trough often lasts only one year, occasionally it lasts several years.

2. Initial TPFR increase (phase 2): The usual sequence of interaction between fertility trends of young and of older women in this phase is as follows: Childbearing postponement of young women continues, possibly at a slower rate. Older women are recuperating births they had postponed when they were younger and their fertility rate is rising. These women manifest a considerable propensity to bear more children at an advanced age to compensate for the earlier postponed births. The absolute extent of childbearing recuperation exceeds that of the continuing childbearing postponement of young women at that time. The interplay of continuing childbearing postponement and strong recuperation is reflected in a TPFR increase. In reality it might happen that for a limited or lengthy period of time the recuperation of childbear- 
ing of older women is offset by an approximately similar extent of continued childbearing postponement resulting in a relatively stable TPFR. In sum, the TPFR is usually increasing in phase 2, but there can be periods during which the TPFR trend may be more or less stable.

3. Final TPFR increase (phase 3): Young women have stopped postponing births and their fertility trend is stable. Older women are continuing to recuperate births they had postponed when they were younger and their fertility rate is rising. Thus the TPFR is increasing.

4. Stabilised TPFR (phase 4): Childbearing recuperation has come to an end and there is no childbearing postponement among young women. The total period and cohort fertility rates settle at roughly the same level.

This model provides a standard for assessing the status of the postponement and recuperation process in individual populations (Fig. 5). As will be demonstrated, many Western countries have passed through most of the first three phases of the model. Some have gone through the entire progression. A majority of populations has not completed the cycle by the 2000s and is at a certain point in the progression of events. An approximation of phase 4 appears to be the endpoint for the foreseeable future, but new patterns may emerge. In reality the way in which populations pass through the phases differs from one country to another. Furthermore, some populations do not pass through all the phases, but may skip a phase; in some cases the designation of the phases can be ambiguous.

To construct the model and for purposes of international comparison two simplifying assumptions were adopted. These are inherent in the model and they are applied when following childbearing postponement and recuperation in individual populations.

(a) Total cohort fertility rates are lagged by 30 years, which is a generalisation based on the fact that the mean age of childbearing is increasing in almost all low-fertility populations, and in some has reached the age of $30 .^{13}$

(b) The end of age 28 is taken as the dividing point between young women postponing their births and older women recuperating births. This division might not apply in some populations, however in all of them birth postponement or recuperation tend to be relatively moderate around that age so that any distortions are likely to be minimal.

In the model the trends start at the tail end of the "baby boom" in Western countries presumably in the early 1970 s and with the birth cohorts of the early to mid 1940s. At that point overall fertility is still declining and there is a continued decline in childbearing in the 15-28 age group as well as in the 29-49 age group of women. It was during the 1970s when in the Western countries the average age of child-

13 For evidence on levels and trends in cohort and period average ages of childbearing in the respective populations see Frejka and Sardon (2004) Table CO-12 on pp. 366-367 and graphs on pp. 50, 84, 116, 146, 176, 238-239, 308-309. 
bearing started to increase ${ }^{14}$ that the postponement of fertility commenced. That is expressed in the continuing decline of fertility among the 15-28 years old women. During the late 1970s and early 1980s childbearing among women 29-49 years old levels off. This implies the lack of any fertility recuperation. Once childbearing postponement has been in progress for some time, birth recuperation gets under way in the mid 1980s.

The structural mechanism shaping the trend of total period fertility rates is the interaction between childbearing postponement of younger cohorts and childbearing recuperation of older cohorts. Consequently, the overlay of changing childbearing patterns of relevant birth cohorts at a time when fertility is being delayed and recuperated is reflected in the TPFR trends in low-fertility countries since the early 1970s.

Each of the 36 low-fertility populations for which sufficient data are available has been analysed. The populations have been classified into four groups, two of them with sub-groups, which share similar basic features in the P\&R process. The main criteria for this classification were (i) the birth cohorts in which childbearing postponement started and the period when this occurred; and (ii) closely correlated to this tends to be the year of the TPFR trough. The groups largely overlap with geographical regions and sub-regions. To a large extent the kindred basic features in the P\&R process are due to the fact that in most of the regions and sub-regions countries have common economic, political, social, and frequently also shared linguistic, cultural, ethnic, and other characteristics. The classification is not perfect and the titles of some regions might seem awkward. Some regions are more homogeneous than other. These are as follows: ${ }^{15}$

\section{A. Western countries}

a. Nordic countries: Denmark, Finland, Norway, Sweden.

b. Western Europe: Belgium, England \& Wales, France, Netherlands.

c. West Central Europe: Austria, West Germany, Switzerland.

d. Non-European countries (English-speaking): Australia, Canada, New Zealand, United States.

B. Southern Europe: Greece, Italy, Portugal, Spain.

C. Central and Eastern Europe

a. East Central Europe: Czech Republic, East Germany, Hungary, Poland, Slovak Republic.

b. Eastern Europe: Bulgaria, Romania, Russian Federation.

c. West Balkan Region: Bosnia \& Herzegovina, Croatia, Macedonia, Slovenia, Yugoslavia (including Montenegro and Kosovo).

D. East Asia: Hong Kong, Japan, South Korea, Taiwan.

\footnotetext{
14 See footnote 13.

15 This classification is similar to the one applied in Frejka and Sardon (2004: 21-22).
} 


\section{$4 \quad$ Illustrations and analysis}

For each country an assessment has been made of the main features of the childbearing postponement and recuperation process taking the model as the standard. Illustrations for selected countries are depicted and discussed on the following pages.

\subsection{Western countries}

As a rule, childbearing postponement in the Western countries started among the birth cohorts of the 1940s, usually during the 1970s. The TPFR troughs occurred in a range between 1976 and 1987, mostly in the early to mid 1980s. Interestingly, in several populations troughs were close to the limits of "lowest-low" fertility: 1.38 in Denmark, 1.47 in the Netherlands - both in 1983 - and two years later 1.52 in Switzerland and as low as 1.28 in West Germany.

The experience of the Nordic countries, especially Denmark (Fig. 6, panel A), was reasonably close to the model. Among the countries of Western Europe, the Netherlands closely resembled the standard four phases of the model (Fig. 6, panel B). This population is the only one that has concluded the entire P\&R cycle conclusively. The TPFR and the TCFR have converged at the same level around the year 2000 (Fig. 6, panel B).

The German-speaking populations of West Central Europe, Austria, West Germany and Switzerland, present a totally different picture (Fig. 7, panel A). TPFRs in these countries were relatively stable after reaching the trough. Childbearing postponement which was still continuing in the mid 2000s was being offset by steady but slow recuperation.

Fig. 6: Total cohort fertility rate (lagged by 30 years TCFR (-30)), total period fertility rate (TPFR), cumulative period fertility rates 15-28 (CPFR 15-28) and 29-49 (CPFR 29-49), Denmark and Netherlands, 1970-2006

A. Denmark

Births per woman

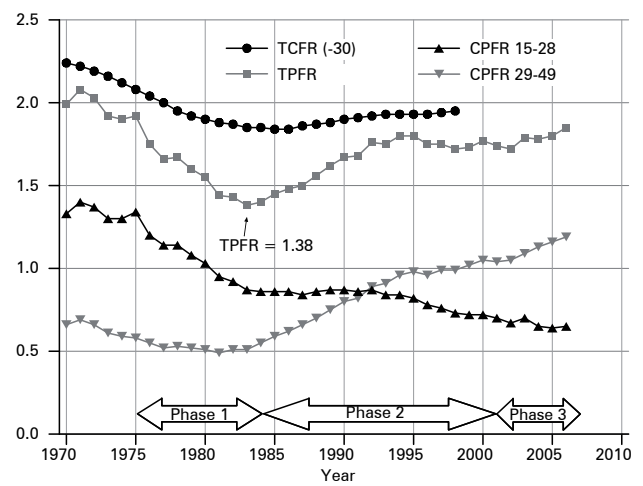

B. Netherlands

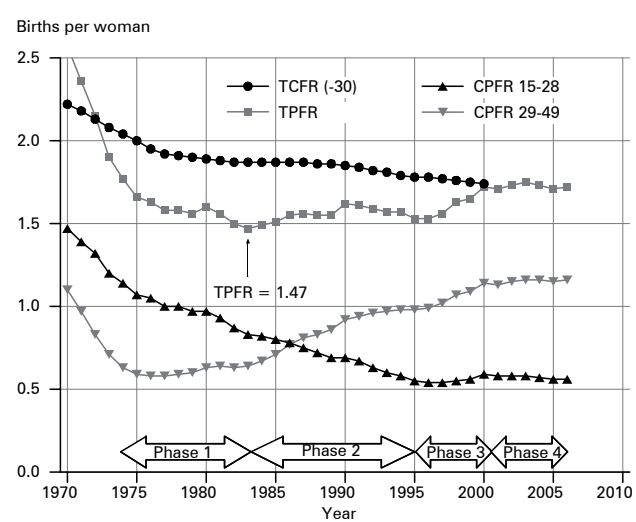

Source: Observatoire Démographique Européen 2010 
Fig. 7: $\quad$ Total cohort fertility rate (lagged by 30 years TCFR (-30)), total period fertility rate (TPFR), cumulative period fertility rates 15-28 (CPFR 15-28) and 29-49 (CPFR 29-49), Switzerland and United States, 1970-2007

\section{A. Switzerland}

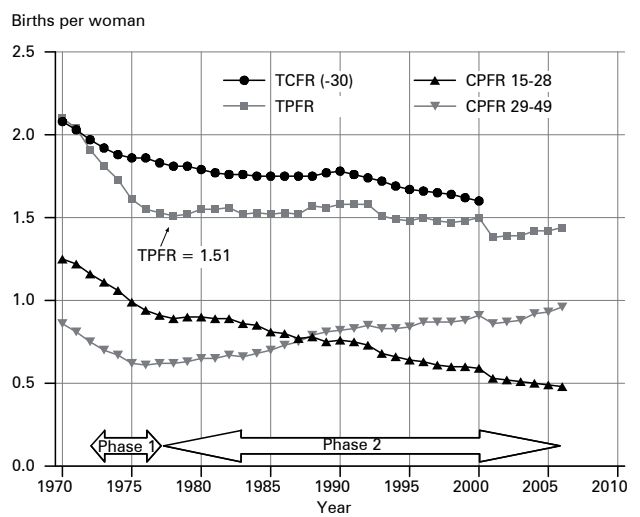

B. United States

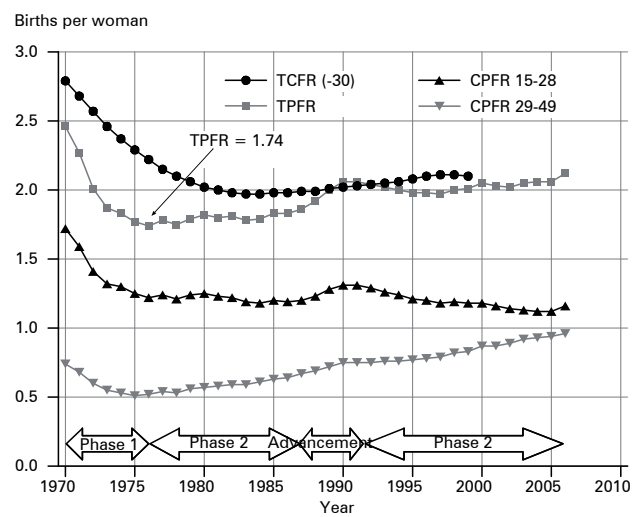

Quelle: Observatoire Démographique Européen 2010

The childbearing postponement and recuperation process and how it unfolded in period measures in the United States' population has been exceptional in several ways (Fig. 7, panel B).

(i) The US population has been a precursor. Childbearing delays started in the US as the first among Western countries during the 1960s and proceeded at a rapid pace during the early 1970s.

(ii) Childbearing postponement came to an abrupt halt in the mid 1970s reflected in an indistinct TPFR trough of 1.74 births per woman in 1976. Thereafter fertility of young women remained stable at a comparatively high level of 1.2 births per woman through the late 1980s. Recuperation started its modest stable long-term increase in the mid 1970s. This combination resulted in a very slow TPFR increase to 1.83 in 1985-86.

(iii) An unusual childbearing advancement, i.e. an increase in fertility mainly of teenage women occurred between about 1986 and 1990. This fertility increase of young women was combined with a continuing modest childbearing recuperation, a fertility increase, among older women and it thus led to a peak in the TPFR of 2.06 births per woman in 1990. Such a "phase" of TPFR increase engendered by a temporary childbearing advancement was a unique episode in the P\&R process in low-fertility countries.

(iv)From 1992 through 2006 childbearing postponement proceeded at a moderate pace as did recuperation. Their respective trends roughly offset each other. Thus the TPFR was quite stable around 2.0 births per woman throughout most of the 1990s and 2000s.

In sum, the big picture of the P\&R process in the United States is one of modest childbearing postponement and moderate recuperation. This might be due to the multi-ethnic composition of the US population and possible offsetting trends be- 
tween the major ethnic groups having different childbearing patterns. Each of the ethnic groups (Whites, African Americans, Hispanic Americans and those of Asian descent) would require separate analyses to determine the differences in the childbearing postponement and recuperation process between these ethnic groups, but thus far data were not available for such a detailed exploration.

\subsection{Southern Europe}

The main developments in South European populations were a considerable childbearing postponement among young women combined with nonexistent or modest recuperation during the 1980s and most of the 1990s. The outcome was very low, "lowest-low", period fertility in Spain (TPFR=1.16 in 1996), Italy (TPFR=1.19 in 1995), and Greece (TPFR=1.24 in 1999), and low fertility in Portugal (TPFR=1.41 in 1995), i.e. troughs in the mid to late 1990s (Fig. 8, panel A). ${ }^{16}$ The P\&R process had not been concluded in the South European countries by the mid 2000s even though fertility of young women was already very low, especially in Italy and Spain. Apparently childbearing postponement among young women was reaching its floor during the mid to late 2000s. Recuperation among older women was still under way and

Fig. 8: Total cohort fertility rate (lagged by 30 years TCFR (-30)), total period fertility rate (TPFR), cumulative period fertility rates $15-28$ (CPFR 15-28) and 29-49 (CPFR 29-49), Greece 1970-2004, and Czech Republic 1970-2006

\section{A. Greece}

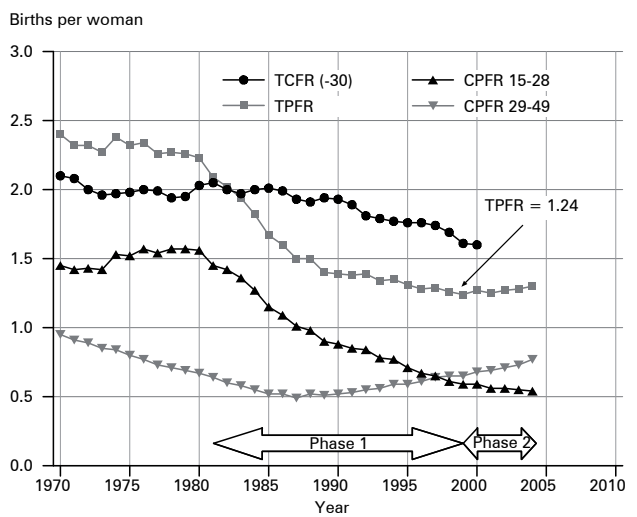

\section{B. Czech Republic}

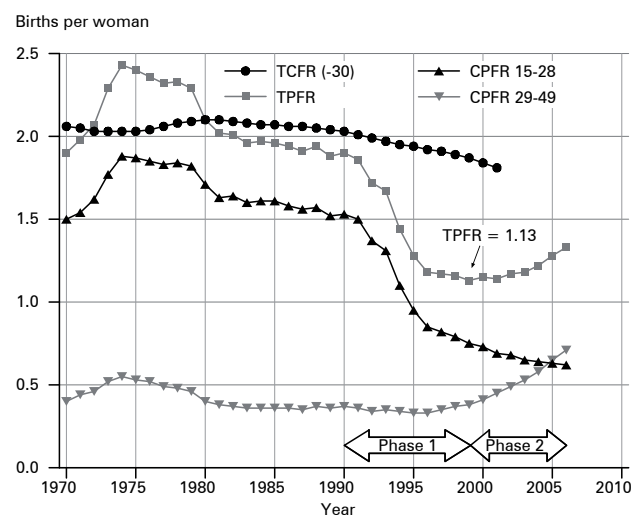

Source: Observatoire Démographique Européen 2010

\footnotetext{
16 The Greek trends constitute one of those cases where the designation of phases is ambiguous. The lowest TPFR value, 1.24, was reached in 1999, and therefore that is the year in which, according to the way in which the phases are distinguished, phase 1 ends. In reality postponement and recuperation trends were offsetting each other since about 1990, but the TPFR in 1990 equaled 1.39 which was higher than in 1999. If one were to apply the latter interpretation, phase 1 would have ended in 1990.
} 
is likely to continue for some years to come, which will be reflected in a continued TPFR increase.

\subsection{Central and Eastern Europe}

There was a great deal of variation between sub-regions and populations in the large region of Central and Eastern Europe. No matter when postponement started, for the most part around 1990, it was considerable and proceeded at a rapid pace from one birth cohort to the next. In almost all countries of Central and Eastern Europe TPFRs declined to unusually low levels labelled as "lowest-low" fertility (Kohler et al. 2002). The rapid childbearing postponement was reflected in the TPFRs troughs of the countries of East Central Europe around the year 2000: 1.13 in 1999 in the Czech Republic, 1.18 in 2002 in Slovakia, 1.22 in 2003 in Poland, and 1.27 also in 2003 in Hungary.

A detailed analysis of the underlying changes in cohort childbearing patterns and their overlap using data from the Czech Republic (Fig. 8, panel B) will demonstrate why TPFRs declined at an unprecedented rapid pace during phase one and why they reached such low levels.

1. During the mid to late 1990s, women of the cohorts born in the late 1950s and early 1960s had very low fertility when they were in their thirties and forties because they had borne most of their children when they were young (Fig. 9, panels A and B). Typically their lifetime childbearing age patterns were young, usually peaking around the ages of 21 and 22 with a high concentration of childbearing in their late teens and early to mid twenties.

2. A gradual decline in fertility started among the late 1950 s and early 1960 s birth cohorts, even though these were hardly postponing any of their births.

3. The shift of childbearing into higher ages started among the late 1960s and early 1970s birth cohorts and then accelerated among the mid-1970s cohorts. Note the considerable difference in the slope of the 1958 and the 1978 cohorts up to age 21 (Fig. 9, panels A and B). Fertility was declining rapidly among young women of successive cohorts of the early to mid 1970 s and this was reflected in rapid declines of period fertility among young women between the ages 15 and 28 (CPFR 15-28) during the 1990s and in the rapid decline of the TPFR (Fig. 8, panel B).

In sum, the overlay of the low fertility of older women of the late 1950s-early 1960 s birth cohorts with the rapidly declining and relatively low fertility of young women of the mid to late 1970s birth cohorts resulted in the period fertility trough of a TPFR equal to 1.13 in 1999 in the Czech Republic (Fig. 8 [panel B] and 9 [panel $\mathrm{B}])$. It was the rapid pace of the childbearing age pattern shifts that were an important factor in generating the period fertility trough. While the total cohort fertility rates (TCFR (-30)) of the corresponding birth cohorts were declining only moderately (Fig. 8 , panel B), the rapid fertility decline among young women due to the fast pace of postponement was driving the rapid rate of TPFR decline in the years prior to 1999. Compared to most Western countries childbearing postponement in Central East European countries started about two decades later, i.e. around 1990 
Fig. 9: Cohort age-specific fertility rates, Czech Republic, birth cohorts 1958-1982

A. Childbearing shifts into higher ages

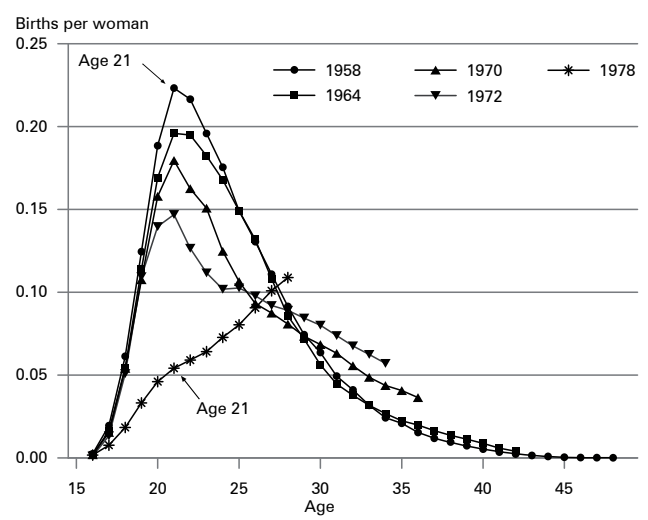

B. Succession of birth cohorts

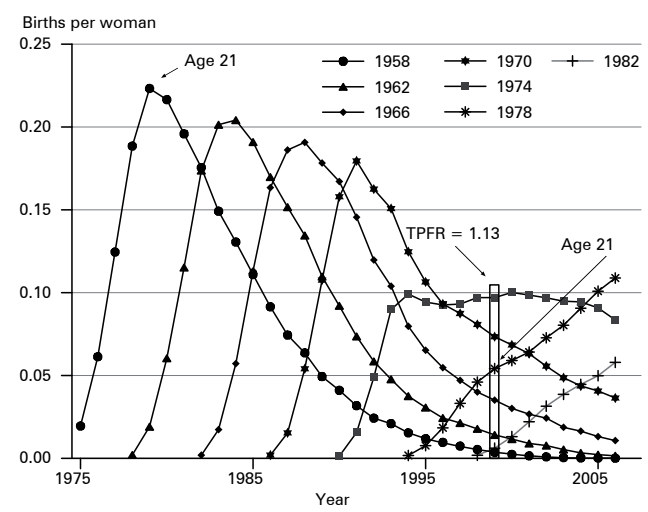

Source: Observatoire Démographique Européen 2010

rather than in the 1970s, and proceeded at a much faster pace. "Lowest-low" TPFR troughs close to 1.2 births per woman were reached around the year 2000, down from about 2.0 in 1990.

The basic nature of the beginning of the postponement and the recuperation process was similar in Eastern Europe. During the 1990s fertility declined rapidly among young women which was reflected in a fast TPFR decline. "Lowest-low" TPFR troughs of 1.1 to 1.3 births per woman were reached in the mid to late $1990 \mathrm{~s}$.

Fig. 10: Total cohort fertility rate (lagged by 30 years TCFR $(-30)$ ), total period fertility rate (TPFR), cumulative period fertility rates 15-28 (CPFR 15-28) and 29-49 (CPFR 29-49), Russian Federation and Croatia, 1970-2006

A. Russian Federation

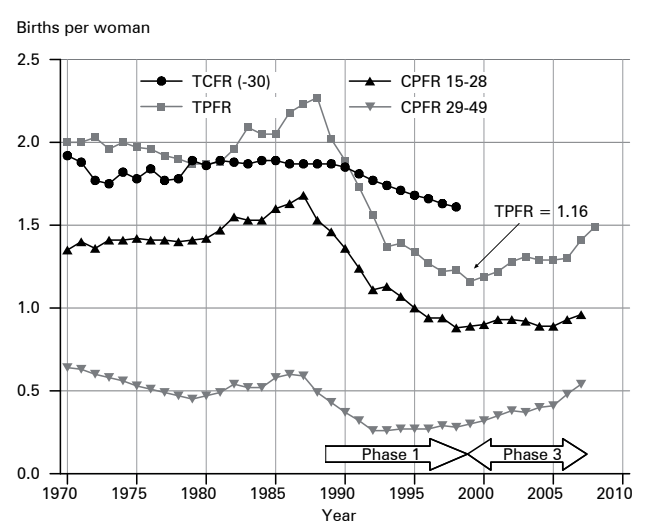

B. Croatia

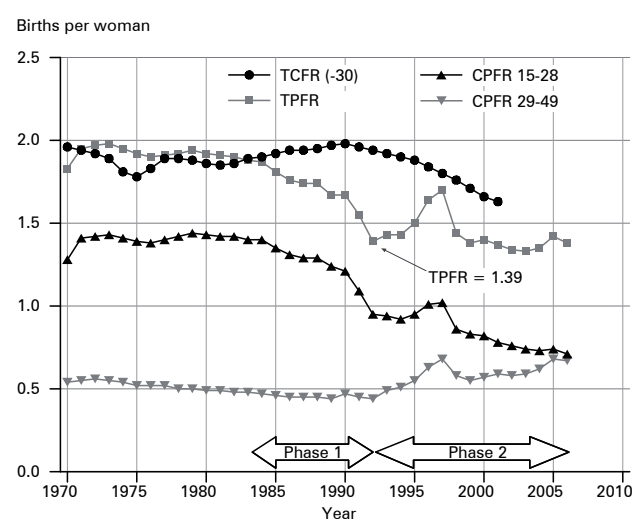

Source: Human Fertility Database; Observatoire Démographique Européen 2010 
At the same time, Russia's period fertility trends were influenced by a number of policy interventions since the 1980s (Zakharov 2008). The effect of the 1980s Soviet pronatalist policies and their aftermath make it difficult to pinpoint when childbearing postponement started, most probably around 1990. The end of phase one - a rapid fertility decline among young women during the 1990s and stable fertility among older women through the late 1990s - was reached in 1999 with a TPFR trough of 1.16 births per woman (Fig. 10, panel A). In 2008, however, the TPFR was at 1.49 births per woman, an increase of $28 \%$ over the 1999 trough. In part that was influenced by another policy intervention, the Putin childbearing incentives of 2006, which had a positive impact on fertility at all ages, even in 2009 (Frejka 2009).

Wars affected demographic trends significantly in the West Balkan region, particularly in Bosnia \& Herzegovina, Croatia and Yugoslavia, less so in Slovenia and Macedonia. The decline of fertility among Croatia's young women was relatively moderate between the mid 1980s and 1992. After the 1992 trough of 1.39 fertility trends were interrupted by a "post-war mini baby boom." Except for this increase in fertility during the late 1990s, the postponement trend was offset by a recuperation trend (Fig. 10, panel B).

\subsection{East Asia}

The long-term demographic history of Japan is very different than that of Hong Kong, South Korea, Singapore and Taiwan. At the time when Japan reached replacement fertility in the mid-1950s, the other countries of East Asia still had TPFRs of five to seven births per woman. During the following decades fertility declined rapidly in Hong Kong, South Korea, Singapore and Taiwan reaching replacement fertility in the 1980s. The fertility decline in all five populations continued and by the mid to late 2000 s period fertility rates in these countries were among the lowest in the world, termed "ultra-low fertility" by Jones, Straughan, and Chan (2009). In 2005 the TPFR was 0.97 in Hong Kong, 1.11 in Taiwan, 1.12 in South Korea, 1.25 in Singapore, and 1.23 in Japan (Frejka et al. 2010).

Since the mid 1970s the basic feature of the childbearing P\&R process has been reasonably uniform in these four populations. Childbearing delays had been continuing at least for over two decades prior to the mid to late 2000s and childbearing recuperation was considerably weaker than birth postponement.

In Japan the combination of steadily declining fertility of young women and stable fertility of older women resulted in a continuously declining TPFR, especially following the brief upswing of childbearing recovery in the mid 1980s (Fig. 11, panel A). The robust propensity to delay births throughout the late $20^{\text {th }}$ and persisting in the early $21^{\text {st }}$ century is characteristic of the other populations in this region, Hong Kong, Taiwan and South Korea (Fig. 11, panel B). In the mid 2000s young women had a fertility rate of 0.5 births per woman or less in all countries of the region. The TPFR trough around 1.0 occurred in Hong Kong in 2005, in South Korea in 2003 and had not even been reached by the mid 2000s in Taiwan. 
Fig. 11: Total cohort fertility rate (lagged by 30 years TCFR (-30)), total period fertility rate (TPFR), cumulative period fertility rates 15-28 (CPFR 15-28) and 29-49 (CPFR 29-49), Japan and South Korea, 1970-2007

A. Japan

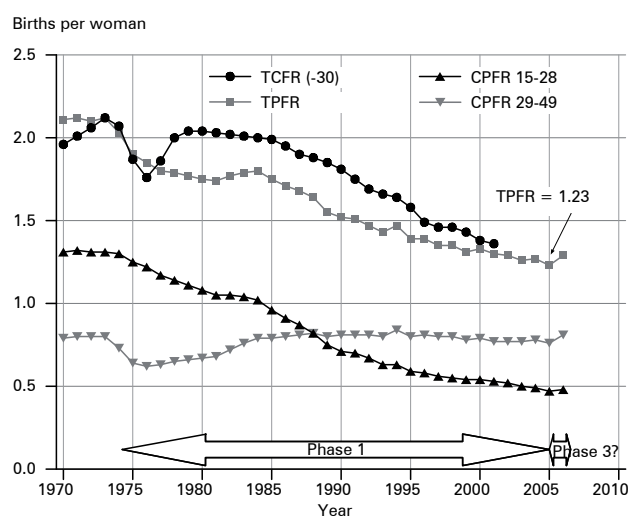

B. South Korea

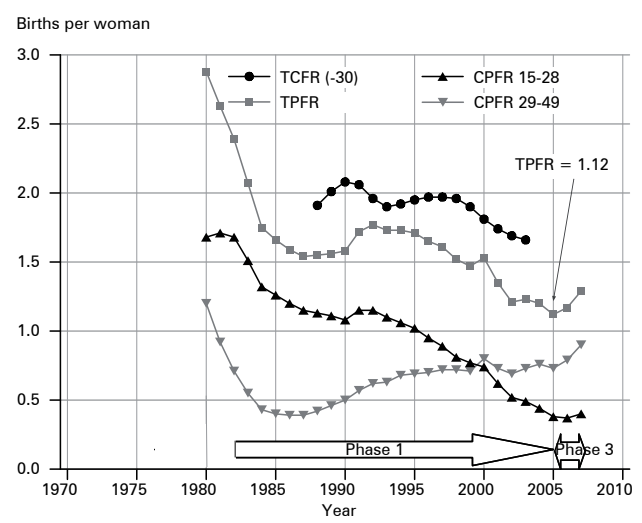

Source: Observatoire Démographique Européen 2010

\subsection{The structural background of TPFR trends}

The above exposition illustrates the utility of analysing the structural background of TPFR trends. TPFR trends which on the surface might appear similar may have different underlying mechanisms, i.e. different levels and trends of interaction between childbearing postponement and recuperation that resulted in the respective TPFR trends. For example, the Dutch population between 1996 and 2000 (Fig. 6, panel B), and the Czech population between 2001 and 2006 (Fig. 8, panel B), both experienced a TPFR increase of approximately 0.2 births per woman, but the underlying mechanisms were different.

In the Netherlands the TPFR increase occurred towards the end of the childbearing P\&R cycle. Postponement had already run its course and had come to a standstill. Recuperation was winding down. The TPFR was coming close to the respective TCFR level (Fig. 6, panel B). In contrast, in the Czech Republic the TPFR was in an early stage of the P\&R process; it had only just passed the TPFR trough. Childbearing postponement was still on a downward slope and poised to continue. Childbearing recuperation had only just started; it was on an upward slope and also poised to continue (Fig. 8, panel B). This example illustrates that the increases of the TPFRs in the late 1990s and the 2000s had different structural backgrounds in different countries. These developments illustrate that it was a historical coincidence that TPFRs were increasing in most low-fertility countries almost simultaneously in the late 1990s and early 2000s. The TPFRs in many low-fertility countries increased roughly at the same time, however for different structural demographic reasons in the Western countries in contrast to the Central and East European countries. 
Moreover, it is important to note that in both cases the TPFR increase was almost exclusively a result of changes in the cohort childbearing age patterns, i.e. changes in fertility timing, and not generated by a quantum fertility increase. The evidence is obvious in the Dutch case. While the TPFR was increasing during the late 1990s, the corresponding TCFRs were declining modestly (Fig. 6, panel B). In the Czech case thus far the evidence is circumstantial and preliminary. TPFRs were increasing during the early to mid 2000s, and, judging from the TCFR trend of the 1960s birth cohorts it can be assumed that corresponding TCFRs of the 1970s birth cohorts might continue to decline or stabilise (Fig. 8, panel B).

\subsection{Applying the method of this paper to possibly re-evaluate some previous studies on causes of fertility trends}

There are numerous factors that have triggered and sustained the childbearing P\&R process. With considerable success these factors have been analysed, discussed and clarified in the literature (see references in section 2). The research elaborated in this study demonstrates that the structural mechanism of the childbearing postponement and the recuperation process is reflected in TPFR trends. By extension, familiarity with the factors driving the childbearing P\&R process is essential to understanding TPFR trends.

Taking this into consideration, the question can be posed whether it might be profitable to revisit some of the research that investigated the causes of period fertility trends which would also utilise the method developed in this study. A comprehensive investigation into the compatibility of the effects of the childbearing P\&R process on period fertility, on the one hand, with research that has analysed the effects of behavioural, socio-economic and policy factors on (period) fertility trends is beyond the scope of this paper. It might, however, be useful to explore, for instance, how the research on the appearance and disappearance of lowest-low fertility due to socio-economic and policy factors (Goldstein et al. 2009; Kohler et al. 2002) can be developed further utilising the method of the present study. Also, an investigation of whether some of the findings assigning fertility increases early in the 21st century either to changed behavioural attitudes of women and couples, or to social and population policies, or to changing economic conditions (Goldstein et al. 2009; Kocourková 2009; Kohler et al. 2002; Myrskylä et al. 2009) might also benefit by applying the method of this paper. Once the method used in the present research is applied and incorporated in the research of these authors their findings might need to be modified.

Total period fertility rate changes tend to be mainly the result of changes in the timing of childbearing rather than the consequence of changes in particular socioeconomic circumstances. For instance, the TPFR increases in populations in the early 21 st century appeared to have been predominantly due to changes in cohort fertility timing and due to certain overlaps of cohort childbearing patterns and not due to direct effects of specified socio-economic factors. The same applies to the appearance and disappearance of TPFR troughs. The effects of socio-economic circumstances on TPFR trends might be operating via the effects on cohort fertility 
timing and not directly on TPFR trends. The influence of these factors might have been different than presumed.

\section{$5 \quad$ Summary and conclusions}

A method that analyses how the process of cohort and period childbearing postponement and recuperation is reflected in total period fertility levels and trends in low-fertility populations during recent decades is outlined in this paper. The method is rooted in the path breaking ideas developed by Ryder (1951 and 1964). The logic forming the foundation of the method is that in reality childbearing postponement and recuperation occurs in the life of individual women and can be summarised in the lifetime experiences of birth cohorts. To analyse the effects of the cohort P\&R process on total period fertility rates, cohort childbearing age patterns are translated into period childbearing age patterns. The effects of the P\&R process on the TPFRs are revealed by summarising period age-specific fertility rates of young women and of older women and analysing their interaction over time. The method is complementary to methods pioneered by Bongaarts and Feeney (1998) which estimate tempo-adjusted period total fertility rates. The B \& F method and its variations demonstrate the degree to which total period fertility rates are distorted, i.e. the extent to which TPFRs would be different if there would be no changes in the timing of childbearing. The method described in this paper can be characterised as revealing the internal mechanism generating TPFR trends; it exposes the demographic structural causes generating TPFR trends and demonstrates why TPFRs are moving in a certain direction based on the trends in childbearing behaviour of young and older women.

The analysis of the process of cohort and period childbearing postponement and recuperation in low-fertility populations during the past half century yields the following findings.

1. Total period fertility rates always descend in the initial years of the childbearing postponement and recuperation process. These TPFR declines occur because in the initial years of the childbearing P\&R process fertility decreases among young women whereas initially there are no or only minor offsetting increases in the fertility of older women in overlaying birth cohorts. Any childbearing recuperation takes place only after the respective cohorts have aged, i.e. fertility increases of older women come to pass with a time delay. Therefore any increase in fertility of older women offsetting fertility declines of younger women usually occurs only several years after the commencement of childbearing postponement. The initial TPFR descent occurs because the size of the fertility decline among young women outweighs any possible initial increase in fertility among older women.

2. TPFR troughs appear at the end of the initial phase of the childbearing P\&R process. The troughs occur because low fertility among young women of 
young cohorts postponing childbearing overlaps with low fertility among older women of older cohorts who had not postponed births. The structural reason for a TPFR trough to take place is a relatively low fertility among young women of the overlapping younger cohorts because their childbearing already started to descend. Fertility is also relatively low among the older women in the overlapping older cohorts because these experienced young childbearing age patterns, i.e. they had borne most of their children when they were young. Hence the combination which results in a TPFR trough. This state was labelled as "lowest-low fertility" in South, East and Central Europe. The troughs occurred earlier also in Western countries where they were not noticed and not considered noteworthy and unusual at the time.

3. Total period fertility rates were increasing in almost all low-fertility countries in the late 1990s and in the early $21^{\text {st }}$ century, however, the structural causes of this increase were different in Western countries compared to those in Central and Eastern Europe. In Western countries populations were experiencing the concluding phases of the P\&R process, i.e. postponement had ceased and recuperation was still ongoing. TPFRs were coming very close to the levels of corresponding total cohort fertility rates. In contrast, in Central and Eastern Europe populations were experiencing the initial phases of childbearing P\&R, i.e. postponement was still ongoing and recuperation had only just started. There was still a gap between the TPFRs and the corresponding TCFRs. It was a historical coincidence that TPFRs were increasing in most low-fertility countries almost simultaneously in the late 1990s and early 2000 s.

4. The increases in total period fertility rates in the late 1990s and in the early $21^{\text {st }}$ century were predominantly the result of changing childbearing age patterns, i.e. changes in timing, and were not due to increased fertility quanta. Essentially, during this period in almost all the low-fertility countries TPFRs were rising while corresponding total cohort fertility rates were declining.

5. As expected on theoretical grounds, contemporary historical experience confirms that after the cessation in childbearing postponement and once recuperation works its way through the main periods of the childbearing ages, total period fertility rates resemble total cohort fertility rates. Any further fertility trends depend on overall quantum trends. This happened early in the $21^{\text {st }}$ century in The Netherlands. New waves of fertility postponement or advancement may occur in the future. For the time being, the childbearing postponement and recuperation process of the last decades of the $20^{\text {th }}$ century and of the early $21^{\text {st }}$ century is ending, although in several countries the cessation of the P\&R process might still take many years.

6. All low-fertility populations were experiencing the P\&R process in the late $20^{\text {th }}$ and early $21^{\text {st }}$ centuries, but there was a great deal of variation. Some countries were experiencing a considerable childbearing recuperation and 
their TPFRs came close to replacement. In other countries recuperation was minimal and their TPFRs were very low around $50 \%$ below replacement.

7. Imprecise regional patterns of the P\&R progression have emerged. There were differences in the specific paths of the childbearing postponement and recuperation processes between country populations, nonetheless some basic features tended to be common within regions. The above processes started in Western countries predominantly during the 1970s and continued during the next four decades. In Central and Eastern Europe they started predominantly during the 1990s and were ongoing in the 2000s. The typical cycle in Western countries consisted of a TPFR decline in the 1970s and early 1980s, a trough in the early to mid 1980s, a TPFR increase in the late 1980s, and nearing conclusion in the 2000s. In Central and Eastern Europe typically a rapid TPFR decline occurred during the 1990s, the period fertility trough appeared in the late 1990s or early 2000s, and a TPFR increase tended to occur in the 2000s. The populations of Southern Europe and East Asia experienced long periods of childbearing postponement usually starting in the 1980s combined with weak or almost nonexistent fertility recuperation. Consequently TPFRs were at best stable, but more often declining for many years. In some populations in the 2000s, such as Italy and especially Spain, childbearing postponement approached a floor and a moderate fertility recuperation resulted in TPFR increases.

8. Findings of some studies investigating the effect of societal factors on the TPFR level and trends should be re-examined. It might be useful to explore whether the findings on how changing childbearing age patterns of overlapping birth cohorts which are reflected in period fertility declines, troughs and subsequent TPFR increases, on the one hand, can be reconciled with research findings attributing the appearance and disappearance of lowestlow fertility as well as increases in period fertility in the $21^{\text {st }}$ century directly to social, economic and other causes.

9. Given that fertility trends of young people tend to be different from those of older people, it appears prudent to investigate childbearing motivations and societal environments in which childbearing decisions are made separately for each group. Often this is done subconsciously, it should however be done consciously and explicitly, when appropriate. Within a specific period of time the general societal environment is common for young and older people, however, different age and social groups are likely to perceive, or be subject to, varying sets of childbearing incentives and disincentives.

The method outlined and discussed in this paper has several limitations. Motivations for the respective childbearing behaviour are not specified nor is the economic, social, political, policy, historical, in short the societal environment in which childbearing behaviour takes place, depicted. For that the reader has to consult 
other literature. Furthermore, in the country analyses the same age dividing young women from older ones has been applied in all populations. In fact, this age differs between populations and within populations over time. Inaccuracies are introduced by applying an identical dividing age in all populations. To ascertain the actual dividing age for each population throughout the respective time span and to apply it in the analysis would have grossly complicated the project and the results would not have been much different. Also, total cohort fertility rates were lagged by 30 years in all populations and over time. Actually, TCFRs should be lagged by the average age of childbearing for each cohort. Comparisons of the TPFRs and the TCFRs in the country graphs would then be slightly more theoretically correct, but the differences would be minor. Finally, a technical note: The analysis is a conceptually simple procedure, but it requires detailed statistical data, and consists of several indispensable steps, which have to be performed to reach useful results.

Notwithstanding these limitations, the research presented here has significant relevance and use. The following are among the more meaningful advancements of this research:

- It elucidates the structural demographic causes of TPFR trends, in general, and the causes for the TPFR troughs and of the TPFR increases during the late 1990 s and in the early $21^{\text {st }}$ century, in particular. By exposing the structural demographic causes of TPFR trends, this research provides a base or background for analysing social, economic, political, cultural, ethnic, normative and other causes of change in TPFR trends in recent decades.

- It provides a base for analysing the variation in TPFR trends between countries and regions.

- It provides the logic for analysing causes of TPFR trends separately for young and for older women even when they are exposed to the same societal environment.

- Researchers and policy makers in individual countries can get an idea of the stage in which their population finds itself in the postponement and recuperation process, and provides a feeling of what may lie ahead, albeit uncertain.

It is advisable to conduct these analyses in conjunction with new methods of fertility analysis and forecasting, for instance, new methods of analysing and projecting cohort fertility (Sobotka et al. 2011).

\section{Acknowledgements}

The author wishes to thank anonymous reviewers as well as colleagues for valuable comments on numerous earlier drafts, namely John Bongaarts, Jan Hoem, Ron Lesthaeghe, John Ross, Jean-Paul Sardon, Tomáš Sobotka and Charles Westoff. 


\section{References}

Billari, Francesco C. 2008: Lowest-low fertility in Europe: Exploring the causes and finding some surprises. In: Japanese Journal of Population 6,1: 2-18.

Billari, Francesco C.; Kohler, Hans-Peter 2004: Patterns of low and very low fertility in Europe. In: Population Studies 58,2: 161-176.

Bongaarts, John 2001: Fertility and Reproductive Preferences in Post-Transitional Societies. In: Population and Development Review. Supplement to Vol. 21: 260-281 [doi: 10.2307/3115260].

Bongaarts, John 2002: The end of the fertility transition in the developed world. In: Population and Development Review 28,3: 419-433 [doi: 10.1111/j.1728-4457.2002.00419.x].

Bongaarts, John; Feeney, Griffith 1998: On the quantum and tempo of fertility. In: Population and Development Review 24,2: 271-291.

Bongaarts, John; Feeney, Griffith 2006: The quantum and tempo of life cycle events. In: Vienna Yearbook of Population Research 2006: 115-151.

Bongaarts, John; Sobotka, Tomáš 2010: Demographic explanations for the recent rise in Europe's fertility. Paper presented at the European Population Conference, Vienna, 2 September 2010.

Bourgeois-Pichat, Jean 1987: The Unprecedented Shortage of Births in Europe. In: Population and Development Review, Supplement to Vol. 12: 3-25.

Calot, Gérard; Blayo, Chantal 1982: The recent course of fertility in Western Europe. In: Population Studies 36,3: 349-372.

Chasteland, Jean-Claude; Chesnais, Jean-Claude (Eds.) 1997: La population du monde: enjeux et problems. In: Travaux et Documents 139. Paris: INED.

Chesnais, Jean-Claude 1998: Below-Replacement Fertility in the European Union (EU-15): Facts and Policies, 1960-1997. In: Review of Population and Social Policy 7: 83-101.

Frejka, Tomas 2008: Determinants of family formation and childbearing during the societal transition in Central and Eastern Europe. Overview Chapter 5. In: Frejka, Tomas et al. (Eds.): Childbearing trends and policies in Europe. In: Demographic Research, Special Collection 7, Vol. 19,7: 139-170 [doi: 10.4054/DemRes.2008.19.7].

Frejka, Tomas 2009: Russia and Germany: Some similarities and many differences in fertility patterns and trajectories. Conference on Challenges in Family and Fertility Development in Russia and Germany, 07.-08. December [http://www.dia-dem.de/].

Frejka, Tomas 2010: Cohort overlays of evolving childbearing patterns: How postponement and recuperation are reflected in period fertility trends. MPIDR Working Paper WP-2010-026.

Frejka, Tomas; Jones, Gavin W.; Sardon, Jean-Paul 2010: East Asia childbearing patterns and policy developments. In: Population and Development Review 36,3: 579-606. [doi: 10.1111/j.1728-4457.2010.00347.x]

Frejka, Tomas; Ross, John 2001: Paths to Subreplacement Fertility: The Empirical Evidence. In: Population and Development Review, Supplement to Vol. 21: 213-254.

Frejka, Tomas; Sardon, Jean-Paul 2004: Childbearing trends and prospects in low-fertility countries. Volume 13, European Studies of Population. Dordrecht: Kluwer Academic Publishers.

Frejka, Tomas; Sardon, Jean-Paul 2009: Contemporary childbearing trends in low-fertility countries. Paper presented at the $X X V I^{\text {th }}$ IUSSP International Population Conference, Marrakech, Marocco. 27.09.-02.10.2009. 
Frejka, Tomas et al. (Eds.) 2008: Childbearing trends and policies in Europe. Demographic Research, Special Collection 7, Vol. 19,1-29: 1-1178.

Goldstein, Joshua R.; Sobotka, Tomáš; Jasilione, Aiva 2009: The end of 'Lowest-Low' Fertility? In: Population and Development Review 35,4: 663-699 [doi: 10.1111/j.17284457.2009.00304.x].

Hajnal, John 1947: The analysis of birth statistics in the light of the recent international recovery of the birth-rate. In: Population Studies 1,2: 137-164.

Hajnal, John 1950: Births, Marriages and Reproductivity, England and Wales, 1938-47. In: Reports and Selected papers of the Statistics Committee, pp. 303-422. Papers of the Royal Commission on Population, vol. II. London: His Majesty's Stationary Office.

Hobcraft, John 1996: Fertility in England and Wales: A Fifty Year Perspective. In: Population Studies 50,3: 485-524 [doi: 10.1080/0032472031000149586].

Jones, Gavin W.; Straughan, Paulin; Tay, Chan Angelique (Eds.) 2009: Ultra-low Fertility in Pacific Asia: Trends, causes and policy issues. Routledge, Taylor \& Francis Group, London and New York.

Kirk, Dudley 1946: Europe's Population in the Interwar Years. Geneva: League of Nations.

Kocourková, Jiřina 2009: The Current 'Baby boom' in the Czech Republic and Family Policy. In: Czech Demography 3: 43-53.

Kohler, Hans-Peter; Billari, Francesco C.; Ortega, José Antonio 2002: The emergence of lowest-low fertility in Europe during the 1990s. In: Population and Development Review 28,4: 641-680 [doi: abs/10.1111/j.1728-4457.2002.00641.x].

Lesthaeghe, Ron 1995: The second demographic transition in Western countries: An interpretation. In: Mason, Karen Oppenheim; Jensen, An-Magritt (Eds.): Gender and family change in industrialized countries. Oxford: Clarendon Press: 17-62.

Lesthaeghe, Ron 2001: Postponement and recuperation: Recent fertility trends and forecasts in six Western European countries. IPD Working Paper 2001-1, Interface Demography, VUB, Brussels.

Lesthaeghe, Ron; van de Kaa, Dirk J. 1986: "Twee demografische transities?" In: van de Kaa, Dirk J.; Lesthaeghe Ron (Eds.): Bevolking: groei en krimp. Van Loghum Slaterus, Deventer: 9-24.

Lesthaeghe, Ron; Willems, Paul 1999: Is low fertility a temporary phenomenon in the European Union? In: Population and Development Review 25,2: 211-228 [doi: abs/10.1111/ j.1728-4457.1999.00211.x].

Myrskylä, Mikko; Kohler, Hans-Peter; Billari, Francesco C. 2009: Advances in development reverse fertility declines. In: Nature 460: 741-743 [doi: 10.1038/nature08230].

Ní Bhrolcháin, Máire; Toulemon, Laurent 2005: Does postponement explain the trend to later childbearing in France? In: Vienna Yearbook of Population Research 2005: 83-107 [doi: 10.1553/populationyearbook2005s83].

Observatoire Démographique Européen 2010: Data Bank. St. Germain-en-Laye, France.

Ortega, José Antonio; Kohler, Hans-Peter 2002: Measuring low fertility. Rethinking demographic methods. MPIDR Working Paper 2002-001. Max Planck Institute for Demographic Research. Rostock. Accessed at [www.demogr.mpg.de/publications/working. htm].

Philipov, Dimiter; Kohler, Hans-Peter 2001: Tempo effects in the fertility decline in Eastern Europe: Evidence from Bulgaria, the Czech Republic, Hungary, Poland and Russia. In: European Journal of Population 17,1: 37-60 [doi: 10.1023/A:1010740213453]. 
Ryder, Norman B. 1951: The cohort approach: Essays in the measurement of temporal variations in demographic behavior. PhD dissertation, Princeton University.

Ryder, Norman B. 1964: The process of demographic translation. In: Demography 1,1: 57-82.

Ryder, Norman B. 1986: Observations on the History of Cohort Fertility in the United States. In: Population and Development Review 12,4: 617-643.

Sauvy, Alfred 1948 : La réprise de la natalité dans le monde. Ses causes, ses chances de durée. In: Population 3,2: 249-270.

Sardon, Jean-Paul 2004: Recent Demographic Trends in the Developed Countries. In: Population (English version) 59,2: 263-314.

Schoen, Robert 2004: Timing effects and the interpretation of period fertility. In: Demography 41,4: 801-819 [doi: 10.1353/dem.2004.0036].

Sobotka, Tomáš 2003: Tempo-quantum and period-cohort interplay in fertility changes in Europe. Evidence from the Czech Republic, Italy, the Netherlands and Sweden. In: Demographic Research 8,6: 151-213 [doi:10.4054/DemRes.2003.8.6].

Sobotka, Tomáš 2004a: Is lowest-low fertility explained by the postponement of childbearing? In: Population and Development Review 3,2: 195-220 [doi: 10.1111/j.17284457.2004.010_1.x].

Sobotka, Tomáš 2004b: Postponement of childbearing and low fertility in Europe. PhD Thesis. University of Groningen. Amsterdam: Dutch University Press.

Sobotka, Tomáš; Lutz, Wolfgang 2009: Misleading Policy Messages from the Period TFR: Should We Stop Using It? In: European Demographic Research Papers 4. Vienna: Vienna Institute of Demography [http://www.oeaw.ac.at/vid/download/edrp_4_09.pdf].

Sobotka, Tomáš; Toulemon, Laurent 2008: Changing family and partnership behaviour: Common trends and persistent diversity across Europe. Overview Chapter 4 In: Frejka, Tomas et al. (Eds.): Childbearing trends and policies in Europe. Demographic Research, Special Collection 7, Vol. 19,3: 85-138 [doi: 10.4054/DemRes.2008.19.6].

Sobotka, Tomáš; Zeman, Kryštof; Lesthaeghe, Ron; Frejka, Tomas 2011: Postponement and recuperation in cohort fertility: New analytical and projection methods and their application. In: European Demographic Research Papers 2. Vienna: Vienna Institute of Demography.

Teitelbaum, Michael S.; Winter, Jay M. 1985: The Fear of Population Decline. London: Academic Press Inc.

van Imhoff, Evert 2001: On the impossibility of inferring cohort fertility measures from period fertility measures. In: Demographic Research 5,2: 23-64 [doi:10.4054/ DemRes.2001.5.2] [www.demographic-research.org].

Westoff, Charles F. 1983: Fertility Decline in the West: Causes and Prospects. In: Population and Development Review 9,1: 99-104.

Zakharov, S. 2008: Russian Federation: From the first to the second demographic transition. In: Frejka, Tomas; Hoem, Jan M.; Sobotka, Tomáš; Toulemon, Laurent (Eds.): Childbearing Trends and Policies in Europe. Max Planck Institute for Demographic Research: 907-972 [doi:10.4054/DemRes.2008.19.24] [http://www.demographic-research.org/special/7]. 


\begin{abstract}
A German translation of this reviewed and author's authorised original article by the Federal Institute for Population Research is available under the title "Die Auswirkung des aktuellen Aufschubs und Nachholens von Geburten auf die Ausprägung der Periodenfertilitätstrends", DOI 10.4232/10. CPoS-2011-20de or URN urn:nbn:de:bib-cpos-2011-20de7, at http://www.comparativepopulationstudies.de.
\end{abstract}

Date of submission: 12.09 .2011

Date of Acceptance: 01.03.2012

Dr. Tomas Frejka ( $\triangle)$. Independent Consultant, Sanibel, Florida, USA.

E-Mail: tfrejka@aol.com 


\section{Comparative Population Studies - Zeitschrift für Bevölkerungswissenschaft}

wWw.comparativepopulationstudies.de

ISSN: 1869-8980 (Print) - 1869-8999 (Internet)

Published by / Herausgegeben von

Prof. Dr. Norbert F. Schneider

Federal Institute for Population Research

D-65180 Wiesbaden / Germany

Managing Editor /

Verantwortlicher Redakteur

Frank Swiaczny

Editorial Assistant /

Redaktionsassistenz

Katrin Schiefer

Language \& Copy Editor (English) /

Lektorat \& Übersetzungen (englisch)

Amelie Franke

Copy Editor (German) /

Lektorat (deutsch)

Dr. Evelyn Grünheid

\section{Layout / Satz}

Beatriz Feiler-Fuchs

E-mail: cpos@destatis.de

\author{
Scientific Advisory Board / \\ Wissenschaftlicher Beirat \\ Jürgen Dorbritz (Wiesbaden) \\ Paul Gans (Mannheim) \\ Johannes Huinink (Bremen) \\ Marc Luy (Wien) \\ Clara H. Mulder (Groningen) \\ Notburga Ott (Bochum) \\ Peter Preisendörfer (Mainz)
}

\section{Board of Reviewers / Gutachterbeirat} Martin Abraham (Erlangen) Laura Bernardi (Lausanne) Hansjörg Bucher (Bonn) Claudia Diehl (Göttingen) Andreas Diekmann (Zürich) Gabriele Doblhammer-Reiter (Rostock) Henriette Engelhardt-Wölfler (Bamberg) E.-Jürgen Flöthmann (Bielefeld) Alexia Fürnkranz-Prskawetz (Wien) Beat Fux (Zürich) Joshua Goldstein (Rostock) Karsten Hank (Köln) Sonja Haug (Regensburg) Franz-Josef Kemper (Berlin) Michaela Kreyenfeld (Rostock) Aart C. Liefbroer (Den Haag) Kurt Lüscher (Konstanz) Dimiter Philipov (Wien) Tomáš Sobotka (Wien) Heike Trappe (Rostock) 